\title{
Anamorphic Art as an Urban Intervention Strategy
}

\author{
Jéssica Rabito Chaves \\ Universidade Federal de Mato Grosso do Sul - UFMS | Brazil | jessica-jrc@hotmail.com
}

Gilfranco Medeiros Alves

Universidade Federal de Mato Grosso do Sul - UFMS | Brazil | gilfranco.alves@ufms.br

\begin{abstract}
The study is based on the current context of digital creation methodologies and aims to discuss the use of the Anamorphic technique as Urban Art and its role in the creation of new meanings. That objective is to study the technique of Anamorphosis as an instrument that enhances public space, allowing the creation of a work of artistic value as a means of appropriating free spaces. By means of four actions carried out within a research group of a Brazilian public university, the relations between anamorphic object and observers were analyzed from Peircean Semiotics.
\end{abstract}

Keywords: Anamorphosis technique; Urban art; Peirce; Cyberculture; Cyber semiotics.

\section{INTRODUÇÃO}

Esse artigo foi desenvolvido como parte do projeto de pesquisa "Cultura Digital e Processos Digitais de Projeto" junto ao grupo Algo+Ritmo da UFMS, e propõe uma discussão sobre o uso da anamorfose como uma estratégia para potencializar os espaços públicos. O trabalho relaciona-se com o tema do SIGRADI 2018, na medida em que se percebe em ações expandidas do campo da arquitetura, como por exemplo instalações que se utilizem da anamorfose, uma possibilidade de desenvolvimento de políticas públicas que incentivem este tipo de abordagem e de processo, visando a ocupação dos espaços públicos.

As cidades contemporâneas, em destaque as metrópoles, vêm configurando-se negativamente em ambientes segregadores, monótonos (sem identidade) e inseguros. Em contraposição à tal situação, existem estudos que convergem em um pensamento mais positivo para o futuro das cidades, a partir de exemplos de ações estratégicas de planejamento urbano, Jane Jacobs (1961), Bentley (et. al 1999), Lerner (2011) e Gehl (2013) são alguns dos teóricos norteados por conceitos que permeiam o microurbanismo. O uso do espaço público pela lógica da dimensão humana e do desenvolvimento social são capazes de promover a vitalidade urbana que, por conseguinte, demanda questões que beneficiem a relação de convívio entre as pessoas e os espaços livres da cidade como resposta à melhoria da qualidade de vida urbana.

A técnica de anamorfose apresenta, portanto, estratégias para intervenção nos espaços públicos, através do direcionamento da visão das pessoas para determinado local, de modo a atrair a atenção do observador, despertando a curiosidade e a possibilidade de gerar novos usos e significados, tanto em relação à obra anamórfica quanto ao espaço nele inserido. Buscou-se investigar a representação da perspectiva distorcida, conhecida como anamorfose ou ilusão $3 \mathrm{D}$, permitindo reflexões sobre como a anamorfose pode potencializar a ocupação das pessoas no espaço público enquanto estratégia de intervenção urbana.

Sob o efeito de anamorfose, conforme o posicionamento e ângulo de visão do observador, adquire-se possibilidades para apreensão de diferentes signos. Em relação à representação, a anamorfose direciona para uma linguagem dinâmica, vinculada com o comportamento sistêmico da cidade. Para a observação desses fenômenos, foram considerados os critérios da Semiótica de Charles S. Peirce, associados em particular com as mudanças ocorridas a partir da mediação digital e a cibercultura de Pierre Lévy, com intuito de propor reflexões contextualizadas para a questão de permanência e estímulo nos espaços livres públicos.

\section{METODOLOGIA}

A potencialidade da representação anamórfica oriunda das leis da perspectiva geral nos conduz para uma breve investigação de suas origens, compreendendo seus principais conceitos e usos, e por fim, aplicá-los no espaço urbano contemporâneo, ressaltando as possibilidades da arte anamórfica como tática de manifestação pública. A análise fundamenta-se nos estudos sobre a linguagem através da Semiótica e Fenomenologia Peirceana junto com estudos sobre a comunicação abordado por Pierre Lévy sobre a Cibercultura (1999), expandindo para o campo do ambiente virtual, o ciberespaço.

$\mathrm{Na}$ etapa de ações práticas, dedicou-se a aplicação e desenvolvimento de instalações anamórficas variadas. Desde o treinamento, por meio de workshops, passando pela produção de protótipos e simulações digitais, por conseguinte houveram intervenções no ambiente semipúblico e público. Também houve a necessidade da 
criação de plataformas online que expande as ações para o ambiente virtual, o ciberespaço.

\section{DISCUSSÕES}

\section{ESTRATÉGIAS DE USO PARA ESPAÇOS PÚBLICOS DE PERMANÊNCIA}

Como problemática corrente nos centros urbanos, os espaços públicos tornaram-se um local de passagem devido ao intenso fluxo do tráfego de veículos, instaurando a sensação de insegurança para permanência nesses espaços. Jane Jacobs (1961) defende o fomento da diversidade urbana, por meio da combinação de usos, diversidade de usuário e horários, priorizando a necessidade de concentração das pessoas nos espaços públicos.

O sistema de espaços livres proporciona a interação entre as pessoas de diversas camadas da sociedade. Enquanto os espaços flexíveis possibilitam uma constante transformação das configurações destas áreas de acordo com as relações socioculturais, ambientais e econômicas. Segundo Jan Gehl (2006), existem três tipos de atividades exteriores no ambiente urbano: 1. Atividades Necessárias; 2. Atividades Opcionais (apenas em lugares favoráveis); 3. Atividades Sociais (resultado do encontro das pessoas);

Sobre a transformação da paisagem urbana, as intervenções ocorrem por necessidade, não um desejo. Lerner (2011) destaca a importância para a recuperação de feridas que o homem produziu à natureza. Para a apropriação do espaço público, o autor prioriza a criação de espaços comunitários, ambiente de troca de idéias e de interação interpessoal. O autor acredita que no urbanismo também é preciso fazer com que a cidade reaja, criar reações positivas e em cadeia sendo indispensável intervir para revitalizar, fazendo com que o organismo (cidade) trabalhe de outra maneira.

Para a melhoria da qualidade do espaço público resultante de atividades sociais, "quanto mais entender a cidade como integração de funções, de renda, de idade, mais encontro, mais vida ela terá" (Lerner, 2011, p.46). Já Bentley (et al 1999) classificam os principais aspectos que influenciam nos modos do usuário de perceber e interagir com o ambiente através de sete conceitos: 1. Legibilidade; 2. Variedade; 3. Personalização; 4. Versatilidade; 5. Imagem apropriada; 6. Riqueza visual; 7. Permeabilidade.

Entre as tipologias de intervenções urbanas, Lerner (2011) classifica em três categorias que geram o efeito de acupuntura urbana: transformação do espaço através da reciclagem, do toque de genialidade e da mudança cultural. A arquiteta Vera Pallamin destaca com base no filósofo Vilém Flusser que 'é impossível conceber uma cidade sem criatividade e autenticidade cultural em todos os campos, o literário, o arquitetônico, o estético (artes plásticas, pintura, música, etc.)" (Pallamin, 2002, p. 33). E ainda ressalta: "Flusser dirá que só terá realmente êxito uma cidade brasileira que consiga desenvolver esse elemento cultural novo, que salve para os 'novos códigos' (isto é, os códigos da era digital) aspectos relevantes do código tradicional. Se for possível salvar os valores da velha cultura, não os abandonar, não ignorar esses valores, mas incorporá-los a uma nova forma, em uma nova simbiose, um novo sincretismo, o da era digital, então a verdadeira cidade brasileira estaria emergindo em espaços urbanos contemporâneos privilegiados" (Pallamin, 2002, p. 33-34).

Sob o recorte da presente pesquisa, as intervenções urbanas temporárias de enfoque artístico permitem que a instalação seja observada além de uma forma de expressão, mas como uma forma de conhecimento, possibilitando o desenvolvimento cultural e o estímulo do olhar dos cidadãos para a cidade.

\section{O EFEITO DE ANAMORFOSE}

O efeito anamórfico consiste em estruturas que se transformam de acordo com a perspectiva do observador. Em relação a técnica de anamorfose, entende-se por uma representação que inicialmente aparenta um caráter indecifrável e geralmente com proporções distorcidas, porém, a partir da observação sob determinado ponto de vista específico ou sob objeto reflexivo, a representação transfigura-se e adquire proporções reais e tridimensionais, parecendo real. A técnica de anamorfose, segundo Flores (2007), surgiu na época do renascimento e até hoje tem sido utilizada tanto como efeito quanto suporte para visualização.

A anamorfose ocorre através da alteração da perspectiva, Medeiros (2014) descreve que o olhar em perspectiva ocorre quando o plano de projeção se encontra perpendicular ao eixo do cone de visão (Figura 1a). Porém, para o observador identificar a imagem disforme, o ângulo entre o plano de projeção e o eixo do cone de visão tende a ser oblíquo (Figura 1b), percebe-se que a imagem sofreu um deslocamento angular a partir de um de seus extremos, gerando uma distorção.
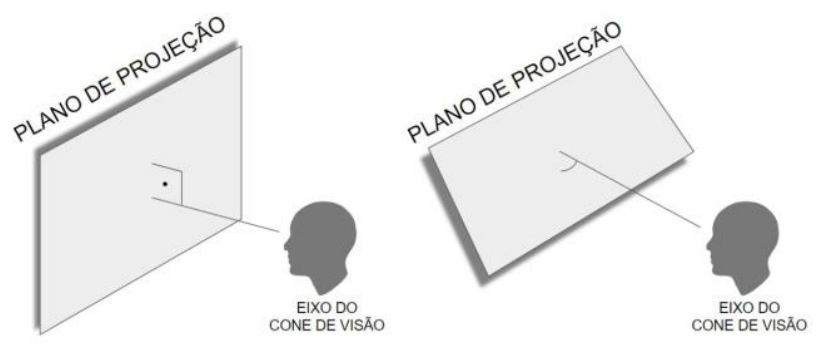

Figura 1: a. ângulo de visão perpendicular (perspectiva padrão). b. ângulo de visão oblíquo (perspectiva anamórfica). Fonte: Autores.

O observador de anamorfose é denominado por Collins (1992) por ser um observador excêntrico, devido seu potencial de autoconsciência em relação ao processo de percepção visual. Destaca-se também que o ponto de observação da representação anamórfica deve ser analisado além de uma resposta à tradicional ênfase adquirida pela visão centralizadora, abordado em 1988 por Arnheim em The Power of the Center, o autor considera a técnica de anamorfose como uma forma de oposição à construção clássica de visão em que o sujeito se encontra articulado em um universo de proporções, matematicamente coerentes.

Por meio de imagens anamórficas, "a mecânica da visão se coloca em primeiro plano em uma relação sujeito e objeto que já não está limitada por convenções típicas de 'olhar'" (Collins, 1992, p.74). O autor sugere que a partir 
do momento que a obra de arte ou objeto de visão tornase o centro, o espectador deixa de ser o centro do mundo.

A perspectiva central, conforme Flores (2003), é considerada inerente ao mundo real como linguagem única, justa e verdadeira quando planificado o objeto e visualizado no espaço tridimensional. A autora refere como sendo de "linguagem única" no sentido de que a perspectiva central fosse a única adequada para leitura de todas as imagens. Tal constatação é consequência da normatização que a perspectiva central adquiriu ao longo do tempo em nossa sociedade.

\section{TÉCNICAS E APLICAÇÕES DA ANAMORFOSE}

Durante a época do Renascimento, diversos artistas buscavam representar o volume e a proporção, a partir do uso da técnica de ponto de fuga, a perspectiva. Já no período Barroco, Andrea Pozzo escreveu importante tratado voltado para pintores e arquitetos, Perspectiva Pictorum et Architectorum, publicado no século XVII. Pozzo desenvolveu um método que na época revolucionou o modo de se projetar o interior de uma cúpula diante de superfícies planas. Embora fizesse uso de regras matemáticas para tal, também empregou noções puramente empíricas, através do processo de como o olho percebe a tridimensionalidade e seu efeito de ilusão.

Já nos séculos XIX e XX foram marcados por práticas artísticas e midiáticas, com estudos voltados para a produção do movimento através de equipamentos de simulação e técnicas cinemáticas, consequências da inclusão da dimensão temporal no campo da Arte (Santaella, 2008). Configurado por uma tenacidade ao movimento, e consequentemente a uma "estética do tempo" gerou-se desdobramentos para o campo da Arte Moderna e Contemporânea, neste período ocorre a ruptura dos preceitos da estética tradicional que enaltece a forma fixa, o imutável e o duradouro.

Na era contemporânea, o efeito de anamorfose encontrase em nosso cotidiano, seja na sinalização horizontal de trânsito que necessita da deformação anamórfica para tornar legível o aviso ao condutor a uma certa distância de segurança, seja na publicidade transmitida nos jogos de futebol - ao lado da trave do gol, temos um tapete com a publicidade anamórfica, que sob o ponto focal das câmeras é possível visualizar a ilusão de totem semelhante ao elemento vertical que permeia no campo. Em ambos os casos, na maioria das vezes o efeito anamórfico passa de modo despercebido, demonstrando como está convencionado este fenômeno em nossa sociedade.

Devido ao efeito visual que surpreende, a anamorfose também é usualmente explorada no campo da publicidade, frequentemente em propagandas audiovisuais e em videoclipes musicais, como por exemplo a campanha Criança Esperança 2016 (Brasil). No campo do espetáculo e da corporeidade, destacamos a utilização da técnica durante a cerimônia de abertura das Olimpíadas Rio 2016, o emprego da técnica de anamorfose com auxílio de projeção mapeada (video mapping) possibilitou criar virtualmente elementos cenográficos dinâmicos em que os atores interagiam com a projeção animada de alusão a edifícios que emergiam e desmoronavam sob o gramado do estádio Maracanã, Rio de Janeiro (Brasil).

A aplicação lúdica desta técnica anamórfica agrega o caráter de deslumbramento, com potencial de atrair a atenção de quem observa - determinada representação de anamorfose - e não identifica ou reconhece o que é, até $\mathrm{o}$ momento em que o observador se posiciona no ponto de vista 'correto', planejado pelo artista, para revelar sua forma ideal. Com base na pesquisa e coleta de dados para identificação das diferentes intervenções que utilizaram a anamorfose em seu processo, classificamos cinco principais linhas de trabalho (quadro 1).

Quadro 1: Linhas de trabalho com aplicação da técnica de anamorfose. Fonte: Autores.

\begin{tabular}{|c|c|c|}
\hline $\begin{array}{l}\text { Aplicação } \\
\text { Anamorfose }\end{array}$ & $\begin{array}{l}\text { Exemplo de } \\
\text { Artistas }\end{array}$ & Observações \\
\hline $\begin{array}{l}\text { 1. Intervenção } \\
\text { urbana de } \\
\text { foco social }\end{array}$ & $\begin{array}{l}\text { Coletivo Boa } \\
\text { Mistura; } \\
\text { Jeroen } \\
\text { Koolhaas; } \\
\text { Dre Urhahn; }\end{array}$ & $\begin{array}{l}\text { Ressaltam como a } \\
\text { pintura pode } \\
\text { transformar a realidade } \\
\text { de comunidades. }\end{array}$ \\
\hline $\begin{array}{l}\text { 2. Tipografia, } \\
\text { arquitetura e } \\
\text { sinalização } \\
\text { urbana }\end{array}$ & $\begin{array}{l}\text { Axel } \\
\text { Peemöller; } \\
\text { Joseph Egam }\end{array}$ & $\begin{array}{l}\text { Exploram a técnica de } \\
\text { tipografia. }\end{array}$ \\
\hline $\begin{array}{l}\text { 3. Arquitetura } \\
\text { e formas } \\
\text { geométricas }\end{array}$ & Felice Varini & $\begin{array}{l}\text { Intervenções } \\
\text { geometrias } \\
\text { anamórficas de desde } \\
1979 \text { e em diferentes } \\
\text { escalas. }\end{array}$ \\
\hline 4. Esculturas & Jonty Hurwitz & $\begin{array}{l}\text { Através do reflexo de } \\
\text { espelho cilíndrico é } \\
\text { possível observar } \\
\text { imagem sem distorção. }\end{array}$ \\
\hline $\begin{array}{l}\text { 5. Cenários de } \\
\text { ilusão 3D }\end{array}$ & $\begin{array}{l}\text { Edgar } \\
\text { Mueller; } \\
\text { Julian Beever }\end{array}$ & $\begin{array}{l}\text { Causam ilusão de ótica } \\
\text { quando vistas por } \\
\text { câmera fotográfica. } \\
\text { Também presente em } \\
\text { efeitos especiais no } \\
\text { cinema. }\end{array}$ \\
\hline
\end{tabular}

Constatou-se que a técnica se caracteriza pela possibilidade de diálogo entre vários universos artísticos, devido ao seu caráter expressivo e de ser considerado de grande potencial criativo, permeando em diferentes escalas de intervenção que impactam em diferentes níveis de interação entre os observadores.

\section{SEMIÓTICA E FENOMENOLOGIA PEIRCEANA: ESTUDO DA LINGUAGEM, MEDIAÇÃO E EXPERIÊNCIA}

Da premissa proposta por Santaella (1983), a semiótica refere à ciência de toda e qualquer linguagem (signo). O signo quanto linguagem contempla linguagens verbais $e$ não-verbais. Para além do uso do idioma às mais variadas formas de linguagem "somos capazes de produzir, criar, 
reproduzir, transformar e consumir, ou seja, ver-ouvir-ler para que possamos nos comunicar uns com os outros". Portanto o "nosso estar-no-mundo, como indivíduos sociais que somos, é mediado por uma rede intrincada e plural de linguagem" (ibid., p.10).

É importante entendermos o conceito de semiose como "o processo no qual o signo tem um efeito cognitivo sobre o intérprete". (Peirce apud Nöth, 2003), tal termo técnico contempla a tríade peirceana (signo, objeto e interpretante) e refere ao processo de interpretação que envolve a ação do signo que acarreta na significação de algo. A semiose ocorre quando o elemento age de modo representativo (como uma representação). Peirce aborda o signo de toda e qualquer coisa como representação de determinado objeto, jamais sendo o objeto em si.

A obra de caráter anamórfico permite diferentes níveis de dinâmica dos signos, que carregam determinado valor simbólico e que devido o efeito anamórfico, o significado transforma-se conforme o ponto de vista do observador, possibilitando assim em uma soma de representações para além de um exclusivo objeto ou mensagem de transmissão em uma mesma obra, graças à característica essencial que possui a técnica de anamorfose.

Quanto ao conceito de Fenômeno compreendemos como "qualquer coisa que esteja de algum modo e em qualquer sentido presente à mente" (Santaella, 1983, p.32), logo a fenomenologia peirceana parte de quaisquer julgamentos, seja pela experiência dela própria. A fenomenologia tem como função "levantar os elementos ou características que pertencem a todos os fenômenos e participam de todas as experiências" (ibid., 1983, p.33).

Quanto ao conceito de mediação e a nossa relação com a realidade, compreende-se como resultado de diálogos com a realidade. Sendo realidade direta aquilo que é físico e nos afeta diretamente, porém a nossa percepção de realidade é no mínimo mediada pelo nosso próprio raciocínio lógico.

Portanto quando estamos em contato "direto" ainda existe mediação, pois o objeto ainda é afetado pela significação do interpretante - este é mediado pela nossa mente diante das nossas próprias experiências. Com isso as interpretações sempre são distintas para cada ser, porém devido à nossa capacidade de conciliação que nos torna hábeis para nos comunicarmos de modo eficiente.

\section{CIBERCULTURA: REDES DE COMUNICAÇÃO}

Sobre a Cibercultura, proposto por Pierre Lévy, final do século $X X$, período marcado por questionamentos acerca dos "impactos" das novas redes de comunicação, devido ascensão da computação e a internet, o autor aponta para o reconhecimento do movimento internacional iniciado pelo interesse dos jovens a experienciar coletivamente, modos de comunicação distintas das mídias tradicionais. Considerado otimista pelos críticos da época, o autor acredita na relevância do papel da internet para a sociedade, diante da possibilidade de proporcionar novos horizontes para o campo da comunicação. Destacando que "cabe apenas a nós explorar as potencialidades mais positivas deste espaço nos planos econômico, político, cultural e humano" (Lévy, 2010, p.11). Entre as abordagens do autor, destaca a consequência da cultura como desdobramento para as áreas da educação, arte e a cidade em benefício da comunicação interativa generalizada.

No sentido que a cibercultura possibilita um novo universo, a conformação de novas culturas advindas após este período é influenciada pelas novas redes de comunicação, condicionadas a determinação do senso de globalização. Lévy sugere que "a cibercultura leva a co-presença das mensagens de volta a seu contexto como ocorria nas sociedades orais, mas em outra escala, em uma órbita completamente diferente" (idem, 1999, p. 15).

Ao mesmo tempo que a técnica anamórfica condiciona o observador, também permite a abertura de outras possibilidades de interpretação ao desbravar determinada intervenção. Conforme Lévy, embora "muitas possibilidades são abertas, e nem todas serão aproveitadas. As mesmas técnicas podem integrar-se a conjuntos culturais bastantes diferentes." (ibid, 1999, p. 25). Como por exemplo, o caso do surgimento das técnicas de perspectiva, tanto a perspectiva linear quanto a perspectiva disforme (anamórfica) surgiram no mesmo período, porém cada qual obteve caminhos diversos, conforme a evolução e desenvolvimento da sociedade, a perspectiva linear protagonizou-se como modelo convencionado para a representação do tridimensional.

\section{ANAMORFOSE COMO ELEMENTO DE COMUNICAÇÃO E INTERATIVIDADE}

A comunicação é integrante característica dos sistemas sígnicos, Lins (1998). Entre as classificações sobre as dimensões de comunicação, explanadas por Lévy (2010), podemos considerar que a técnica de anamorfose se enquadra no campo da linguagem, como tipo de representação. Porém 0 efeito anamórfico envolve aspectos de percepção, de mídia e de codificação no sentido de determinada técnica possuir um princípio de sistema de gravação e transmissão de determinada informação (como por exemplo a anamorfose cônica, que necessita de suporte cilíndrico reflexivo).

Sobre as dimensões de interatividade, ocorrem relações entre a obra anamórfica, o observador como interpretante e o espaço de intervenção. Já no campo do ciberespaço, na esfera do ambiente virtual temos a propagação da intervenção urbana nas redes. Foi utilizado na presente pesquisa, em primeiro momento, como elemento de divulgação por parte da pesquisadora através da criação de contas nas plataformas do instagram, facebook e website. Em segundo momento, verificou-se a divulgação nas redes de modo espontâneo através de fotos, publicações de outros usuários que vivenciaram e tiveram contato "direto" com a obra.

Porém, Lévy (2010) desmistifica a questão da interatividade relacionar apenas ao ambiente virtual. $O$ autor resgata a participação do espectador para a obra e destaca a presença do fenômeno da interatividade ocorrer com qualquer coisa, desde o nosso nascimento. O termo interativo remete a participação ativa do beneficiário (o espectador), e é isso que a semiótica defende como sendo de qualquer natureza. Embora qualquer elemento do universo seja envolvido por interações, existem variações de níveis de interatividade. 


\section{ANAMORFOSE COMO DISPOSITIVO DE INFORMAÇÃO E VIRTUALIZAÇÃO}

A virtualização está presente durante o processo da produção da obra anamórfica, quanto na fase de divulgação pelas redes sociais. "A universalização da cibercultura propaga a co-presença e a interação de quaisquer pontos do espaço físico, social ou informacional. Neste sentido, ela é complementar a uma segunda tendência fundamental, a virtualização" (Lévy, 2010, p. 47).

Quanto a dimensão sensorial virtual, o efeito da anamorfose condiz a classificação de "mundo virtual no sentido de dispositivo informacional", quando "a mensagem é um espaço de interação por proximidade dentro do qual o explorador pode controlar diretamente um representante de si mesmo". O autor exemplifica através de "mapas dinâmicos de dados apresentando a informação em função do 'do ponto de vista', da posição ou do histórico do explorador" (ibid., 2010, p.74).

As redes de comunicação que interagem no ambiente digital, como por exemplo a rede social Facebook e Instagram, permitem a comunicação de acordo com os interesses entre os usuários, envolvendo questões de afetividade, desenvolvendo relações recíprocas e de diálogo. A realidade virtual, no caso das intervenções com os objetos anamórficos, adquire novos significados e integram às mídias de comunicação em que "de fato, várias pessoas geograficamente dispersas podem alimentar simultaneamente uma base de dados por meio de gestos e, em retorno, receber dela informações sensoriais" (ibid., 2010, p. 105).

\section{RESULTADOS}

Os resultados permitiram observar a interação do público em relação tanto com a obra quanto com o espaço nele inserido. $O$ efeito anamórfico instiga o observador a se tornar ativo, atraindo-o para explorar a obra e o espaço, buscando compreender o significado de cada intervenção urbana. Quanto a relevância da apropriação dos espaços públicos, é pertinente a observação de movimentos que busquem alternativas e diferentes atividades para o uso da população nos espaços livres, somadas ao grande potencial da mediação digital, possibilitando conexões e experiências no campo expandido do espaço físico para o virtual.

Assim como Hall Foster relaciona arte e arquitetura como encontro e conexão como um sistema complexo (2017), acredita-se que o processo de construção de uma obra anamórfica se mantém na vanguarda em termos de inovações tecnológicas, adquirindo potencial expressivo, educativo e conectivo. As intervenções, de caráter artístico urbano, somadas à técnica da anamorfose correspondem a uma maneira inusitada de comunicação que desperta diferentes relações entre o espaço e os indivíduos que merecem consideração.

\section{AÇÕES: ETAPA DE EXPERIMENTAÇÃO}

Foram desenvolvidas quatro principais ações que envolveram ao todo nove intervenções lúdicas e artísticas. Em alguns casos com enfoque educacional, como foram os casos das ações do ArqFest, evento de recepção dos calouros, nos anos de 2014 e 2016, voltado para os acadêmicos de Arquitetura e Urbanismo UFMS, teve como objetivo do ensino da técnica e discussão sobre as leis da perspectiva geral, utilizadas na representação de desenho arquitetônico. Destacam-se também as intervenções públicas ocorridas no SESC - Morada dos Baís e no evento multicultural Praça da Bolívia, ambos em Campo Grande-MS, e que serão apresentadas posteriormente.

\section{EXPOSIÇÃO 20 ANOS DE SIGRADI}

A convite do SIGraDi, a equipe integrante do grupo de pesquisa Algo+Ritmo teve como desafio a criação de um protótipo que representasse a edição do XI SIGRADI (La Comunicación en la Comunidad Visual/Comunicação na sociedade visual) realizado no México em 2007 (figura 2a), com base no material do evento e releitura do cartaz de divulgação, identificou-se elementos referentes à circularidade e à comunicação como conceitos estruturantes para a proposta. Buscando a significação de tais conceitos, foram elaborados estudos em direção à representação de redes e conexões a partir do conceito de diagrama tridimensional. Sob a Semiótica de Peirce, um diagrama é um tipo geral de signo que pode ser analisado quanto elemento participativo de determinado processo de pensamento.

O resultado da espacialidade (figura $2 \mathrm{~d}$ ) integrado à função de diagrama possibilitou a representação de uma ideia como um todo. A partir do levantamento dos artigos publicados no congresso de 2007, obteve-se os quantitativos de publicações por país participante, em função dos seus autores, para ser a informação (input) da programação (figura $2 \mathrm{~b}$ ). Propôs-se o desenvolvimento de uma metaball (figura 2c), onde cada esfera representasse um país e os respectivos raios dessas esferas fossem proporcionais ao número de autores identificados. A forma esférica remete ao conceito de comunicação e associada às características de uma metaball teve como intuito destacar o significado de integração entre os países participantes do SIGraDi.

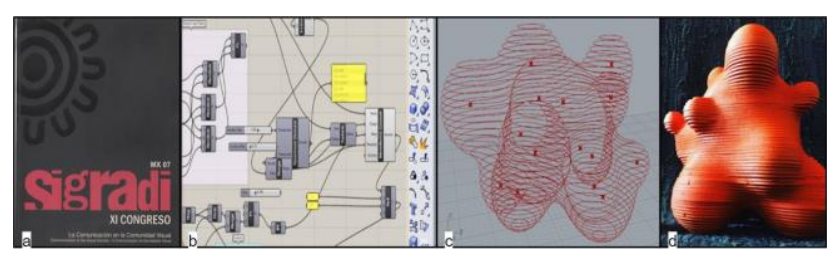

Figura 2: Processo de produção: a.cartaz; b.script; c.maquete virtual; d. Protótipo final. Fonte: Autores.

O desenvolvimento do protótipo para a Exposição de comemoração de 20 anos do SIGraDi, vinculado com a presente pesquisa, contribuíram para discussões acerca da Semiótica e da Anamorfose. É importante compreender que a principal característica da técnica de anamorfose refere-se à possibilidade de determinada representação agregar diferentes informações 'escondidas'. No caso do protótipo desenvolvido para o SIGraDi (figura 2), a sua forma possui informações que variam proporcionalmente a dimensão de cada esfera conforme a quantidade de publicações de cada país (esfera).

\section{OFICINAS DE CAPACITAÇÃO: ANAMORFOSE}

O Argfest é um evento realizado no início de cada semestre, organizado pelos próprios alunos e tem como objetivo envolver todos os acadêmicos do curso de Arquitetura e Urbanismo UFMS durante uma semana com 

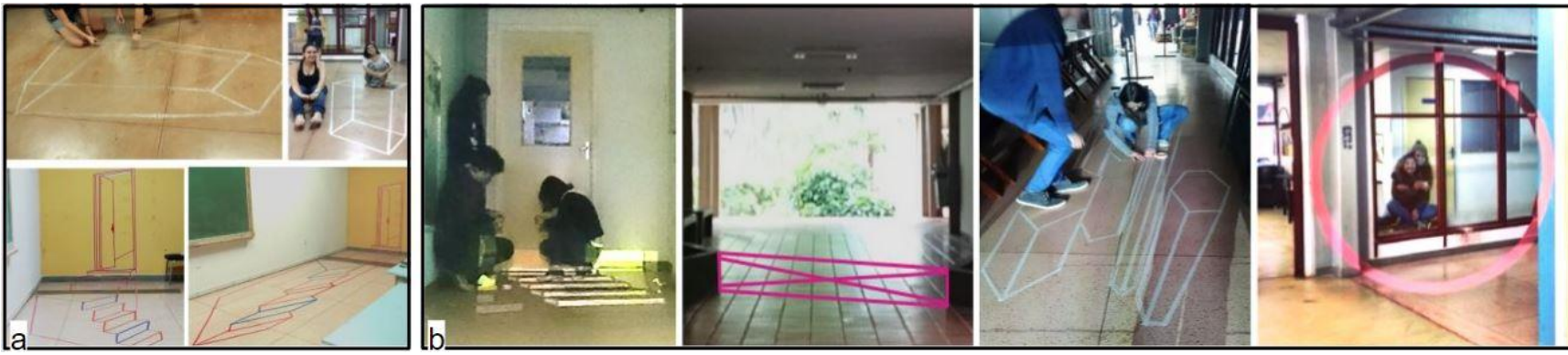

Figura 3: a. Intervenções "o cubo" e "escada ao portal" de cima para baixo (2014). b. Intervenções Lúdicas (2016) grupos 1 a 4, da esquerda para direita. Fonte: Autores.

palestras, debates, oficinas ministradas pelos próprios alunos e diversas intervenções para melhoria do bloco de Arquitetura como pintura de painéis, construção de mobiliário e revitalização de jardins, por exemplo.

A primeira edição da oficina de anamorfose ocorreu no Arqfest 2014, ministrada pelas acadêmicas Jéssica Rabito Chaves e Mariane Delamare, explorou-se a técnica enfatizando o processo rudimentar com predomínio de técnicas analógicas, como uso de barbantes e objetos físicos para modelo, porém mesmo assim houve a necessidade do auxílio de câmera digital ou câmera de celular como instrumento digital. Outro processo digital teve como abordagem a manipulação de projetor conforme altura e angulação do aparelho para deformação da imagem anamórfica in loco e em tempo real (figura 3a).

Na edição de 2016, a semana do Arqfest ocorreu entre os dias 06 e 10 de junho com o tema \#ocupacidades, oficina ministrada pelos acadêmicos Jéssica Rabito Chaves e Vinícius Gonçalves. O foco desta oficina consistiu no processo de teoria e prática: ensino da técnica de Anamorfose com exemplos de aplicações em diferentes campos e em diversos períodos históricos, assim como ações artísticas no bloco de Arquitetura e Urbanismo buscando surpreender os frequentadores destas áreas, possibilitando transmitir alguma mensagem e/ou desenvolver um espírito de apropriação destes espaços.

A oficina de anamorfose teve como pano de fundo a relação com a temática \#ocupacidade, principalmente na fase de aplicação da técnica. A intervenção possibilita realçar o nosso olhar e o das pessoas ao nosso redor, ocupando assim a nossa cidade: do espaço que temos ao espaço que queremos. Os alunos se auto-organizaram em quatro grupos, conforme a afinidade e o interesse da temática de intervenção, sendo cada grupo responsável para intervir dentro do limite do bloco de Arquitetura UFMS. Ao longo do desenvolvimento das intervenções os grupos foram se adaptando de acordo com as limitações ou imprevistos.

Em consequência da limitação de material e equipamentos disponíveis, cada grupo tomou como um desafio a mais na fase de execução, o que acarretou em diferentes formas e técnicas até o final da execução de cada intervenção. O grupo 1 utilizou o software SketchUp para gerar a distorção da imagem, o grupo 2 utilizou-se do software Arena Resolume. Enquanto os grupos 3 e 4 geraram a imagem anamórfica através da posição e inclinação do projetor (figura 3).
Quanto ao tempo de execução, os grupos que terminaram primeiro foram os que intervieram utilizando o projetor como instrumento para gerar imagens anamórficas junto com a utilização de fitas adesivas para finalização. Em comparação, o penúltimo grupo que demandou mais tempo foi devido o uso de tinta de acabamento. Enquanto o grupo que finalizou por último, desenvolveu a técnica de deformação manual e demandou maior tempo para a produção da imagem anamórfica em comparação às equipes que utilizaram o equipamento de projeção para causar o efeito de deformação.

A utilização de softwares tornou possível a deformação da imagem sem alterar a posição ou inclinação do equipamento projetor. Em relação à repercussão das intervenções, durante a semana do Arqfest, constatou-se diante da reação dos frequentadores que tanto os participantes da oficina quanto dos visitantes que transitam por esses espaços foram surpreendidos pelas intervenções, despertando a curiosidade para compreender o motivo da obra estar ali.

\section{ESPAÇO-ENTRE: EXPOSIÇÃO SESC - MORADA DOS BAIS}

A exposição ocorreu de 12 de julho a 13 de agosto 2016 no Sesc Morada dos Baís. Sob a organização do grupo de pesquisa Algo+Ritmo para a criação da exposição com base nos assuntos e trabalhos desenvolvidos pelo grupo, definimos três eixos principais: Video Mapping, Anamorfose e Fabricação Digital. Sendo distribuídas em duas salas, uma para Video Mapping e outra para exposição da escultura anamórfica que tivesse relação com a exposição de Fabricação Digital.

A ideia para concepção da escultura anamórfica surgiu para atender a temática da exposição temporária, que consistia nas mostras dos protótipos impressos em 3D e esculturas de fatiamento com alusão às torres sob a estética de torção. A partir da temática de projeto arquitetônico sob torção, utilizamos como referencial o croqui do arquiteto Calatrava denominado "Torso" o qual o artista se inspirou no corpo humano para desenvolvimento
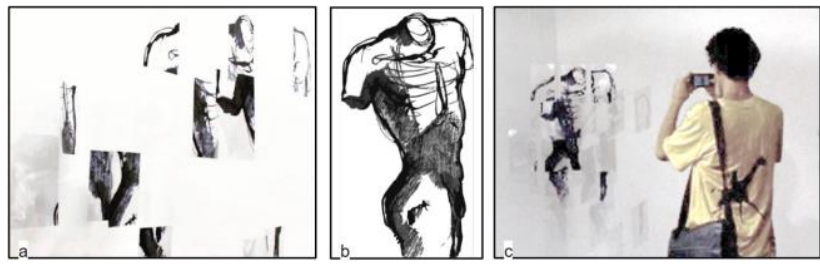

Figura 4: a. visão sob posição aleatória b. visão sob posição idealizada pela artista. c. observador registrando o seu ponto de vista pelo celular. Fonte: Autores. 
projetual do edifício denominado Turning Torso, localizado em Malmö - Suécia.

A escultura do torso desconstruído pode ser considerada uma alusão à arte cinética (figura 4) - quando a obra apresenta movimentação. No caso do torso, a obra estática e o público cinético, visto que o observador necessita se movimentar para ver a imagem do torso se formar e desfragmentar, criando o movimento (figura 4).
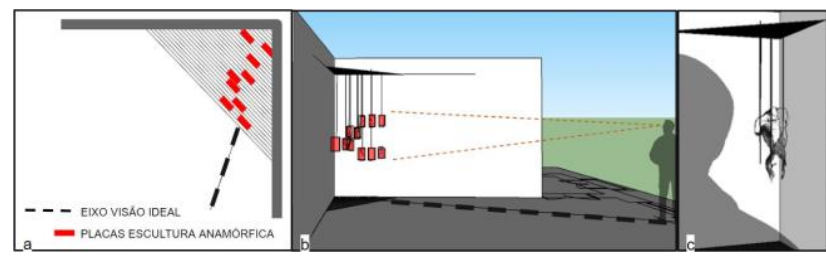

Figura 5: a. Planta; b. Ponto de vista aleatório; c. Ponto de vista ideal. Fonte: Autores.

Para o desenvolvimento da técnica de anamorfose foi utilizado o software SketchUp para a simulação virtual (figura 5), criação de protótipo em escala reduzida, execução da escultura anamórfica e exposição durante um mês no espaço Sesc Morada dos Baís para verificação do potencial de interação entre a escultura anamórfica e o público. Podemos compreender que "a obra se coloca intencionalmente aberta à livre reação do fruidor" (Eco, p.46, 2016), partindo do pressuposto da poética da sugestão.

\section{INTERVENÇÃO URBANA NA PRAÇA DA BOLÍVIA - CAMPO GRANDE/MS}

Para a experimentação da instalação anamórfica em um espaço público, optou-se pela intervenção na praça República da Bolívia, em Campo Grande/MS, ocorrida no dia 14 de maio de 2017, junto com o evento multicultural Praça da Bolívia. A partir da temática do Dia das Mães, foi desenvolvida a representação de um coração anamórfico. Partindo do desenho virtual e do processo de deformação através do uso de equipamento de projeção, a intervenção temporária foi executada com materiais de fácil remoção e baixo custo: fita adesiva e giz de lousa. A intervenção teve como objetivo de que o público fosse atraído ao local em busca de compreender o sentido da imagem sob sua forma ideal (Figura 6a).

A anamorfose foi utilizada como elemento estratégico para despertar a boa ocupação dos espaços livres públicos. A complementação com outras atividades e instrumentos de suporte - que nesta ação temos o caso do evento de feiralivre junto a apresentações artísticas - associados à intervenção anamórfica, houve a potencialização da ação de permanência dos frequentadores no espaço urbano. Entende-se que nesse experimento, inserido no contexto de microespaço urbano, foram analisados a circulação do público dentro do ambiente da praça a partir da análise in loco sobre a reação do público diante da intervenção. Mesmo diante de outras atividades presentes no espaço, verificou-se os níveis de influência da obra sobre atrair os visitantes para determinado local (Figura 6b).

A curiosidade despertada pelos frequentadores, com base em questões sobre o comportamento humano vinculado à percepção cognitiva, envolve estudos sobre a nossa capacidade de interpretação e assimilação sobre a representação em 3D, conceitos referentes ao significado da forma, proposto por Gestalt. Constatou-se que a intervenção anamórfica induziu a maioria dos frequentadores a parar para observar a intervenção e o espaço ao redor, outros tiveram uma interação maior ao nível de realizarem espontaneamente registros fotográficos e compartilhamento nas redes sociais, transpassando a obra para o meio digital.

\section{CONSIDERAÇÕES}

No campo da arte-ciência, as poéticas de recomposição, assim como as ações desta pesquisa, apresentam estudos sobre os processos cognitivos e experiências de arte em rede com a premissa de desbravar tanto o potencial da linguagem da intervenção anamórfica quanto atitudes criativas para os observadores que experienciam a obra dentro do contexto do espaço público. Conferimos para tais poéticas o encargo de singularidade para as obras que permitem ao observador incorporar ou eliminar signos em uma composição, mesmo processada em meios digitais. Deste modo, compreendemos que existe um vínculo entre o público (experienciador) e a obra experienciada que designa uma relação de comunicação.

Sobre as experiências poéticas urbanas, ou a poética do espaço, como proposto por Gaston Bachelard (2008), buscamos proporcionar espaços urbanos qualificados e atrativos, a partir de intervenções centradas na dimensão humana e em recursos disponíveis com a finalidade de estimular reflexões e inovação do espaço urbano e arquitetônico. Durante o processo de construção das obras de intervenção artística, houve a necessidade de se definir cada local de ação em busca de se compreender o 'espírito do lugar', identificando elementos que transformam um espaço urbano aparentemente comum e genérico, como tantos outros lugares no mundo, em um espaço tão específico, afetivo e intrínseco ao imaginário urbano.
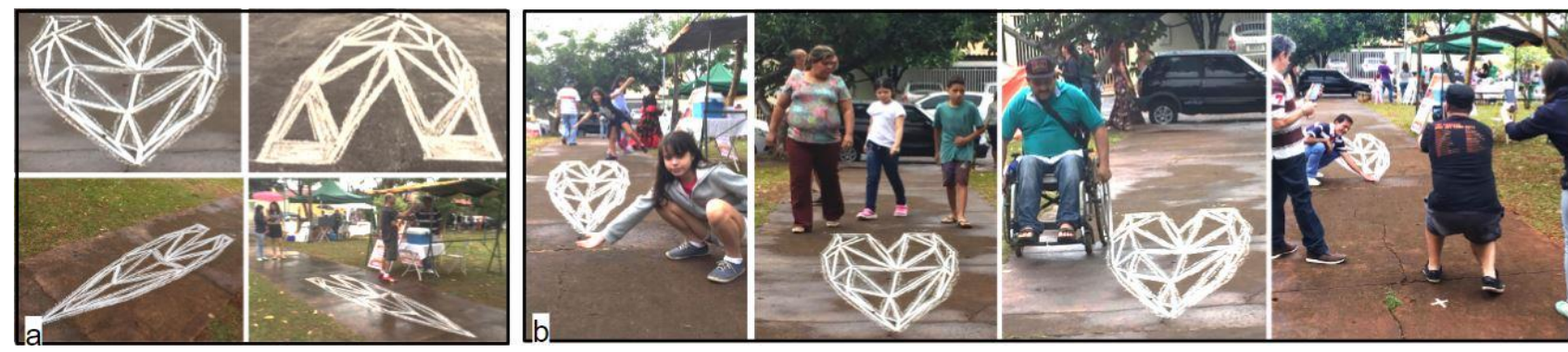

Figura 6: a. Variações conforme o ponto de visão do observador. b. Interação entre público e a intervenção anamórfica. Fonte: Autores. 
Compreendemos que a mediação digital e o ciberespaço permitem outros desdobramentos e reflexões sobre a influência dos cidadãos no desenho urbano, apontando: alternativas metodológicas e políticas de processos em busca de uma arquitetura e de espaços urbanos democráticos, distribuídos e colaborativos consoantes às questões socioambientais. A anamorfose transfigura, desencadeia outras visões de mundo, contrapondo-se com o imediato e convencional, superando o lugarcomum. Por fim, ações artísticas, assim como a anamorfose, nos designam para experiências de caráter fenomênico (perceptivo) e relacional (cognitivo) sobre o espaço.

Aferimos que existem coletivos que utilizam essa técnica para ações sociais, transformando comunidades periféricas, como o Coletivo Boa Mistura (de Madrid, desde 2001). Através das diferentes ações executadas e relatadas nesta pesquisa, constatamos que é possível realizar intervenções anamórficas com baixo custo e com materiais comuns como giz de lousa e fita adesiva, caracterizando em um instrumento democrático e acessível. Portanto, acompanhando os movimentos sociais, acredita-se que a anamorfose pode servir de instrumento adequado para mobilização de ações coletivas em comunidades e escolas, de fomento para ações afirmativas e políticas públicas como mecanismo de empoderamento e de ressignificação urbana.

\section{AGRADECIMENTOS}

Agradecemos ao Conselho Nacional de Desenvolvimento Científico e Tecnológico (CNPq), à Universidade Federal do Mato Grosso do Sul (UFMS), ao grupo de pesquisa Algo+Ritmo. Às contribuições teóricas das disciplinas de Arte e Linguagem I e II ministrada pela professora Dr. Eluiza Bortolotto, Teoria e Estética da Arquitetura e Urbanismo III pelo professor Dr. Gilfranco Alves e Documentário e Semiótica pelo professor Dr. Hélio Augusto Godoy de Souza. Agradecemos também o Comitê Científico Internacional do SIGraDi 2016 pelo convite para exposição de comemoração aos seus 20 anos de edição.

\section{REFERÊNCIAS}

Bentley, I., Alcock, A., \& Murrian, P. (1999). Entornos vitales: Hacia un diseño urbano y arquitectónico más humano manual práctico (No. Sirsi) i9780851399676).

Eco, U. (2016). Obra aberta: forma e indeterminação nas poéticas contemporâneas. Editora Perspectiva SA.

Flores, C. R. (2003). Olhar, saber, representar: ensaios sobre a representação em perspectiva.

Foster, H. (2017). O Complexo arte-arquitetura. Ubu Editora LTDA.

Gehl, J. (2013). Cidades para pessoas

Gehl, J. (2006). La humanización del espacio urbano: la vida social entre los edificios (Vol. 9). Reverté.

Jacobs, J. (2011). Morte e vida de grandes cidades. WMF Martins Fontes.

Lins, A. E. (1998). Diálogo com os signos da arte: ensaios de arte e semiologia. Ser.

Lerner, J. (2011). Acupuntura Urbana. Editora Record, Rio de Janeiro.

Lévy, P. (2010). Cibercultura. Editora 34.

Medeiros, L. S. D. (2014). Anamorfoses em formação: tensionando hábitos e discursos de futuros professores de matemática.

Nöth, W. (2003). Panorama Da Semiótica: de Platão à Peirce. Annablume.

Pallamin, V. M., \& LUDEMANN, M. (2002). Cidade e cultura: esfera pública e transformação urbana. São Paulo: Estação Liberdade.

Santaella, L. (1983). O que é semiótica. Brasiliense.

Santaella, L., \& Arantes, P. (2008). Estéticas Tecnológicas: novos modos de sentir. São Paulo: Educ. 